\title{
Spectrum of clinical features associated with interstitial chromosome 22q11 deletions: a European collaborative study
}

\author{
Department of Human \\ Genetics, University of \\ Newcastle upon Tyne, \\ 19/20 Claremont Place, \\ Newcastle upon Tyne \\ NE2 4AA, UK \\ A K Ryan \\ J A Goodship \\ D I Wilson
}

Centre De Génétique Médicale, Marseille, France

N Philip

A Levy

Abteilung Pädiatrische Genetik,

Kinderpoliklinik, LMU, München, Germany

H Seidel

S Schuffenhauer

Kinderklink, Deutsches

Herzzentrum, TU, München, Germany $\mathrm{H}$ Oechsler

Dr von Haunerschen Kinderspital, LMU, München, Germany B Belohradsky

Hôpital des Enfants Malades, Paris, France M Prieur

Institut Curie, Paris, France

A Aurias

S E Thames Regional Genetics Centre, Guy's Hospital, London, UK F L Raymond

Department of Medical Genetics, St Mary's Hospital, Manchester, UK J Clayton-Smith

Wessex Clinical Genetics Service, Princess Anne Hospital, Southampton, UK

E Hatchwell

Clinical Genetics Unit, Birmingham Women's Hospital,

Birmingham, UK

C McKeown

Clinical Genetics Centre, Utrecht, The Netherlands

F A Beemer

A K Ryan, J A Goodship, D I Wilson, N Philip, A Levy, H Seidel, S Schuffenhauer, H Oechsler, B Belohradsky, M Prieur, A Aurias, F L Raymond, J Clayton-Smith, E Hatchwell, C McKeown, F A Beemer, B Dallapiccola, G Novelli, J A Hurst, J Ignatius, A J Green, $R$ M Winter, L Brueton, K Brøndum-Nielsen, F Stewart, T Van Essen, $M$ Patton, J Paterson, P J Scambler

\begin{abstract}
We present clinical data on 558 patients with deletions within the DiGeorge syndrome critical region of chromosome 22q11. Twenty-eight percent of the cases where parents had been tested had inherited deletions, with a marked excess of maternally inherited deletions (maternal 61, paternal 18). Eight percent of the patients had died, over half of these within a month of birth and the majority within 6 months. All but one of the deaths were the result of congenital heart disease. Clinically significant immunological problems were very uncommon. Nine percent of patients had cleft palate and $32 \%$ had velopharyngeal insufficiency, $60 \%$ of patients were hypocalcaemic, $75 \%$ of patients had cardiac problems, and $36 \%$ of patients who had abdominal ultrasound had a renal abnormality. Sixty-two percent of surviving patients were developmentally normal or had only mild learning problems. The majority of patients were constitutionally small, with $36 \%$ of patients below the 3rd centile for either height or weight parameters. $(\Im$ Med Genet 1997;34:798-804)
\end{abstract}

Keywords: DiGeorge syndrome; velocardiofacial syndrome; chromosome 22q11 deletion

It is now well documented that the majority of cases of DiGeorge syndrome (DGS) and velocardiofacial syndrome (VCFS) result from deletions within chromosome band 22q11. There have been good reviews of each of these syndromes $^{1-3}$ and many case reports drawing attention to new clinical features. ${ }^{4-7}$ The acronym "CATCH 22" (Cardiac, Abnormal facies, Thymic hypoplasia, Cleft palate, and Hypocalcaemia resulting from 22q11 deletions) has been proposed to describe the phenotype. There is wide variability in the clinical spectrum, ránging from problems leading to death in the neonatal period to presentation with isolated hypernasal speech or transient hypoparathyroidism. ${ }^{8-10}$ However, it has been difficult to glean figures for general counselling from published reports. There is a tendency to report atypical cases and published series have been ascertained according to the authors' speciality. ${ }^{112}$ Even the largest of the published series are still too small to provide reliable data for counselling. We have combined data from 23 European centres in an attempt to decrease ascertainment bias and to increase the clinical information on which management and counselling can be based.

\section{Data collection}

Participating centres from Europe were sent data questionnaires relating to cases of proven deletions within chromosome band 22q11. The probes and microsatellite markers used varied between centres but all mapped within the DGS region. ${ }^{2}$ Centres were asked to send information on all their cases, whether previously published or not. The data for all UK centres was collected by one person (AR) who also entered information into the database from the returned questionnaires. Data were requested on heart, palate, renal, and thymus abnormalities, parathyroid function, growth, developmental status, behaviour, and psychiatric illness. All available patient information was entered into an anonymous central database. Some questionnaires did not provide information on all sections, for example, the heart section was completed in more questionnaires than the renal section. Hence, the total number of patients for which data were recorded is specified in each section of the results.

\section{Patient data}

A total of 558 patients were included in the study. In 399 patients, sex was recorded. Of these, $197(49.4 \%)$ were male and 202 $(50.6 \%)$ were female. Excluding the 10 fetuses on which postmortem details were given, ages were available in 534 patients and ranged from birth to 51 years: $286 / 534$ (54\%) were aged 0-5 years, $115(22 \%)$ were aged $6-10$ years, 72 (13\%) were aged 11-17 years, and $61(11 \%)$ were aged 18 years and over. The average maternal and paternal ages at birth were 27.5 and 30.4 years, respectively.

All the people in the study had a deletion within chromosome band 22q11, detected by either fluorescent in situ hybridisation (FISH) or by use of microsatellite polymorphisms mapping within the DGS region. The majority of patients were tested with only one probe. Therefore, no conclusions can be drawn between the size of the deletion and phenotype. 
Università "Tor

Vergata", Rome, Italy

B Dallapiccola

G Novelli

Department of Clinica

Genetics, Oxford, UK

J A Hurst

Department of Medical Genetics, Vaestoliitto, The Family Federation of Finland, Helsinki, Finland

$\mathrm{J}$ Ignatius

Department of Medical Genetics, Addenbrook's NHS Trust, Cambridge, UK

A J Green

Institute of Child Health, London, UK R M Winter

P J Scambler

The Kennedy Galton Centre, Middlesex, UK L Brueton

The John F Kennedy Institute, Glostrup Denmark

K Brøndum-Nielsen

Northern Ireland Regional Genetics Centre, Belfast,

Northern Ireland

F Stewart

Department of Medical Genetics, Groningen, The Netherlands

$T$ Van Essen

Department of Medical Genetics, St George's Hospital Medical School, London, UK M Patton

\section{Duncan Guthrie} Institute of Medical Genetics, Glasgow, UK J Paterson

Correspondence to: Dr Ryan.

Received 5 December 1996 Revised version accepted for publication 17 April 1997
Table 1 Origin of deletions of 285 patients whose parents were also tested for deletions

\begin{tabular}{|c|c|c|c|c|}
\hline & No & $\begin{array}{l}\text { Parent of origin } \\
\text { unknown }\end{array}$ & $\begin{array}{l}\text { Paternal } \\
\text { origin }\end{array}$ & $\begin{array}{l}\text { Maternal } \\
\text { origin }\end{array}$ \\
\hline $\begin{array}{l}\text { De novo } \\
\text { Inherited }\end{array}$ & $\begin{array}{l}204 \\
81\end{array}$ & $\begin{array}{l}167 \\
2\end{array}$ & $\begin{array}{l}24 \\
18\end{array}$ & $\begin{array}{l}13 \\
61\end{array}$ \\
\hline
\end{tabular}

For 285 patients, information regarding parental deletion status was available. For 204/285 $(72 \%)$ patients, both parents were not deleted and therefore these patients had de novo deletions (table 1). Parent of origin de novo deletions were determined in $37 / 204$ (18\%) patients using three microsatellite markers, D22S264, D22S944, and D22S941. There were no unexplained bands that would have raised the suspicion of non-paternity. De novo deletions of the paternally derived chromosome 22 (24) exceeded those from the maternally derived chromosome (13). Inherited deletions occurred in $81 / 285(28 \%)$. For the 81 patients with inherited deletions, the sex of the deleted parent was given in 79 cases. Inherited maternal deletions (61) far outweighed paternal deletions (18). In this group, there were 13 sib pairs, nine with maternal deletions and four with paternal deletions. In the majority of patients with inherited deletions, no information was given regarding whether the normal parent was tested in addition to the deleted parent. In 253 patients, neither parent was tested. There were 20 cases where only one parent had been tested and that parent was not deleted (18 maternal, two paternal).

\section{NEONATAL DETAILS}

Birth weight, gestation, and sex were available for 205 patients. A total of 31/205 (15\%) of babies were born before 37 weeks' gestation. Although 172/205 (84\%) of babies were born within the normal weight range (between the 3rd and 97th centiles), 147/205 (72\%) had birth weights less than the 50th centile and $32 / 205$ (16\%) were below the 3rd centile. Average birth weight was $2960 \mathrm{~g}$ at 38 weeks for males and $2760 \mathrm{~g}$ at 38 weeks for females. Neonatal problems included feeding difficulties, often related to palatal abnormalities, complications secondary to CHD, and seizures secondary to hypocalcaemia.

\section{GROWTH}

Growth data (sex, height, weight, head circumference) were available in 158 patients (table 2). Growth retardation was common; $131 / 158$ $(83 \%)$ of patients had heights/weights less than the 50th centile, and 57/158 (36\%) were below the 3rd centile for either height or weight parameters. In the few cases where there was a discrepancy between height and weight parameters, the height measurement was used; $46 / 120$ (38\%) of patients with congenital heart disease (CHD) were below the 3rd centile for either height or weight compared to $11 / 38$ (29\%) of patients without CHD. This was not statistically significant. Head circumference measures were in keeping with those for height and weight.
Table 2 Comparison of growth parameters in 158 children with and without significant cardiac disease

\begin{tabular}{lcc}
\hline & Normal hearts & $\begin{array}{l}\text { Congenital heart } \\
\text { disease }\end{array}$ \\
\hline Total & 38 & 120 \\
$<75 \% \mathrm{ht} / \mathrm{wt}$ & $36(95 \%)$ & $115(96 \%)$ \\
$<50 \% \mathrm{ht} / \mathrm{wt}$ & $27(71 \%)$ & $104(87 \%)$ \\
$<25 \% \mathrm{ht} / \mathrm{wt}$ & $19(50 \%)$ & $67(56 \%)$ \\
$<3 \% \mathrm{ht} / \mathrm{wt}$ & $11(29 \%)$ & $46(38 \%)$ \\
\hline
\end{tabular}

SURVIVAI

Forty-four patients $(8 \%)$ had died, but the age of death was not given for 15 of these. Of the remaining 29 patients, $16 / 29(55 \%)$ died within one month, and $25 / 29(86 \%)$ had died within six months, as a consequence of CHD. There was one death from severe immune deficiency.

\section{DEVELOPMENT AND BEHAVIOUR}

Information on developmental status was given for 363 patients, but 25 children less than 1 year of age were excluded from analysis as we felt they were too young to exclude mild motor and language delay (table 3); 107/338 (32\%) were reported to be developmentally normal, although 37 of these had speech delay and $231 / 338$ (68\%) had abnormal developmental progress, with severity of delay not recorded in $69 / 338$ (20\%) patients. One hundred and two patients had mild delay. Therefore, 209/338 patients $(62 \%)$ were either normal or had only mild learning problems and 60/338 (18\%) of patients had either moderate or severe learning difficulties.

Of the 252 children aged between 3 and 18 years in our study, $22(9 \%)$ were reported to have either behavioural or psychiatric problems. This included 13 with behavioural problems, six with attention deficit disorder, two with psychosis, and one with mood changes. There were 61 adults (aged $>=18$ years) in our series and $11 / 61(18 \%)$ had a psychiatric disorder. This included $4 / 61$ patients $(6.5 \%)$ who had had at least one episode of psychosis, three patients had a neurotic illness, and four had unspecified psychiatric problems.

\section{CONGENITAL HEART DISEASE}

In 545 patients, cardiac status was recorded. Patients with more than one structural abnormality were grouped under their most clinically significant cardiac abnormality, unless the heart was of very complex arrangement (table 4).

One hundred and ten patients had normal hearts by clinical examination or echocardiogram or both. A further 26 patients had clinically insignificant heart abnormalities, which included five aberrant subclavian arteries and five right sided aortic arches. Therefore, $136 / 545$ patients $(25 \%)$ had no cardiac complications and $409 / 545$ patients $(75 \%)$ had significant cardiac pathology. The group of "other significant abnormalities" included double aortic arch (2), absent pulmonary valve (2), aortic valve stenosis (1), aortic valve hypoplasia (1), coarctation of the aorta (4), double outlet right ventricle (4), atrial isomerism (1), left hypoplastic heart (1), patent ductus 
Table 3 Development of children and adults $(n=338)$

\begin{tabular}{lll}
\hline & No & $\%$ \\
\hline Normal=107 (32\%) & & \\
$\quad$ Normal motor and speech development & 70 & 21 \\
$\quad$ Normal motor development with speech delay & 37 & 11 \\
Abnormal=231 (68\%) & 102 & 30 \\
$\quad$ Mild motor development delay & 51 & 15 \\
Moderate motor development delay & 9 & 3 \\
Severe motor development delay & 69 & 20 \\
\hline Unknown degree of developmental delay & \\
\hline
\end{tabular}

Table 4 The spectrum of heart defects seen in 545 patients

\begin{tabular}{lll}
\hline & No & $\%$ \\
\hline Normal & 110 & 20 \\
Other clinically non-significant & 26 & 5 \\
Tetralogy of Fallot & 95 & 17 \\
Ventricular septal defect & 75 & 14 \\
Interrupted aortic arch & 74 & 14 \\
Pulmonary atresia/ventricular septal defect & 55 & 10 \\
Truncus arteriosis & 51 & 9 \\
Pulmonary valve stenosis & 13 & 2 \\
Atrial septal defect & 8 & 1 \\
Atrioventricular septal defect & 5 & $<1$ \\
Transposition of great arteries & 4 & $<1$ \\
Complex heart disease & 3 & $<1$ \\
Other significant abnormalities & 26 & 5 \\
\hline
\end{tabular}

arteriosis (7), tricuspid valve hypoplasia (1), and unspecified $\mathrm{CHD}$ which required operation (2).

OTOLARYNGEAL ABNORMALTTIES

A total of 242/496 (49\%) patients had otolaryngeal abnormalities (table 5). Seventytwo patients had either an overt cleft palate (hard/soft) or submucous cleft. Cleft lip was present in four patients; two had bilateral cleft lip and palate and two had isolated cleft lip; 161 patients had velopharyngeal insufficiency (VPI) without a cleft.

Data on hearing were available in only 159 patients; 52/159 (33\%) had abnormal hearing and $107 / 159$ had normal hearing (67\%). Of the 52 patients with documented hearing loss there were no further details for 35 cases. In the remaining 17 cases the hearing loss was conductive and most of these patients had palatal abnormalities or recurrent otitis media or both.

\section{GENITOURINARY ABNORMALITIES}

Renal information was given for 136 patients. Abnormalities were present in 49/136 (36\%) patients, including absent, dysplastic, or multicystic kidneys (23), obstructive abnormalities (14), vesicoureteric reflux (6), nephrocalcinosis (1), duplex kidney (1), and unspecified anomalies (4).

Sixteen males had undescended testes $(8 \%$ of total males). The gestation at birth was given for 13 and only two of them were born prema-

Table 5 The spectrum of otolaryngeal complications in 496 patients

\begin{tabular}{lll}
\hline & No & $\%$ \\
\hline Cleft palate (hard/soft) \pm VPI & 45 & 9 \\
Submucous cleft & 25 & 5 \\
Velopharyngeal insufficiency & 161 & 32 \\
Recurrent glue ear/grommets & 11 & 2 \\
Tracheomalacia/laryngomalacia & 9 & 2 \\
Laryngeal web & 6 & 1 \\
Choanal stenosis/atresia & 5 & 1 \\
Other & 13 & 3 \\
\hline
\end{tabular}

turely at 36 weeks' gestation. Six males had a small penis, three had hypospadias, and one had a shawl scrotum.

\section{PARATHYROID FUNCTION}

The parathyroid function and calcium status was recorded for 340 patients; $203 / 340(60 \%)$ had been hypocalcaemic. Of the 108/203 hypocalcaemic patients whose seizure history was documented, $42 / 108$ (39\%) had seizures secondary to hypocalcaemia. Where information was available, the majority of patients responded well to calcium supplements, with cessation of seizures. Although most patients were hypocalcaemic in the neonatal period, several patients were first known to be hypocalcaemic in childhood and one patient presented at 18 years of age. The hypocalcaemia resolved in $45 / 64(70 \%)$ patients and the remainder continue on calcium supplements.

\section{NEUROLOGICAL ABNORMALITIES}

Neurological details were available for 548 patients and $44 / 548(8 \%)$ had neurological abnormalities. Sixteen patients (3\%) had structural brain abnormality, consisting of cerebral atrophy (7), cerebellar hypoplasia (2), cerebral vascular abnormality (1), septum pellucidum cyst (2), hydrocephalus (2), hypoplastic corpus callosum (1), and enlarged ventricles (1). Eleven patients had asymmetrical crying facies (Cayler syndrome), three had 7th cranial nerve palsies, and two had facial asymmetry. One patient, who had had cardiac surgery, had a paralysed hemidiaphragm.

Seizure information was available in 290 patients; $62 / 290(21 \%)$ had seizures and in 42 patients these were hypocalcaemic in origin. Of the other 20 patients, seven were normocalcaemic and in 13 calcium status was unknown. The aetiology of seizures in these 20 patients were unspecified (11), febrile convulsions (6), structural malformations (2), and hyponatraemia (1).

\section{IMMUNE STATUS}

Data on immune function were given for 263 patients, although details were incomplete in many cases (table 6). Patients' white cell count, lymphocyte count, $T$ cell numbers, and clinical history of infections were reviewed. The laboratory data were classified into three groups: major abnormality, minor abnormality, or normal. Those cases in which a clinical history of frequent infections was not recorded were assumed to be clinically normal. Where a patient was reported as having frequent infections (usually of the upper respiratory tract), this was classified as clinically significant. Two patients with severe immune deficiency had died, this being the cause of death in one patient. Presence or absence of the thymus as noted at operation or necropsy was also recorded.

\section{OTHER ABNORMALITIES}

A total of $94 / 548$ (17\%) patients had minor abnormalities of the skeletal system (table 7). Talipes equinovarus and general bone abnormalities were the most frequently seen abnor- 
Table 6 Laboratory and clinical immune and thymus status in 218 patients

\begin{tabular}{llll}
\hline & & \multicolumn{2}{l}{ Clinical history of infection } \\
\cline { 3 - 4 } Laboratory result & $\begin{array}{c}\text { Absent } \\
\text { thymus }\end{array}$ & - & + \\
\hline Major abnormality & 1 & 1 & 2 \\
Minor abnormality & 30 & 132 & 10 \\
Normal & 6 & 70 & 3 \\
\hline
\end{tabular}

Table 7 Range of skeletal abnormalities in 548 patients

\begin{tabular}{lll}
\hline & No & $\%$ \\
\hline Talipes equinovarus & 22 & 4 \\
Other abnormal bones & 22 & 4 \\
Scoliosis & 15 & 3 \\
Abnormal vertebrae & 8 & 1 \\
Polydactyly & 7 & 1 \\
Syndactyly & 6 & 1 \\
Craniosynostosis & 5 & $<1$ \\
Other & 1 & $<1$
\end{tabular}

malities, present in 22 patients (4\%) each, and $39 / 548(7 \%)$ patients had ocular anomalies. Fourteen patients had abnormal teeth, consisting primarily of poor tooth enamel and excess dental caries. Ten patients $(2 \%)$ had anal abnormalities, consisting of anal atresia (2), imperforate anus (3), anteriorly placed anus (2), Hirschsprung disease (2), and constipation (1). Other abnormalities consisted of coloboma (4), hypothyroidism (4), pigmentary abnormalities (2), idiopathic thrombocytopenic purpura (2), and many other isolated structural abnormalities (not listed). While the majority of patients were said to be dysmorphic, there was marked variation, which is shown in fig 1 . The mother and son in fig $1 \mathrm{~A}$ have very subtle dysmorphic features while the mother and son in fig 1B, C, and D have the typical facies. We have made no attempt to analyse these dysmorphic features in detail.

\section{COMPARISON OF PHENOTYPE WITHIN FAMILIES} Parent-offspring comparison

Twenty-seven parents with interstitial deletions of chromosome band 22q11 had 35 deleted offspring. Twenty parents had one affected child, six had two affected children, and one had three affected children. The cardiac defect, palatal abnormality, and developmental status were compared between child and deleted parent when information was available for both. CHD was more severe in $27 / 35$ (77\%) of children compared to their parents, and of the same degree of severity in $8 / 35(23 \%)$. In no case was the child's CHD less severe than his/ her parents. Developmental status was better in $1 / 17(6 \%)$, the same in $7 / 17(41 \%)$, and worse in $9 / 17(53 \%)$. In eight of the nine cases where developmental status was worse, the delay in the child was mild, and in one case the delay was moderate. The palatal abnormalities were better in $10 / 22(45 \%)$ children and similar to the parent's in $12 / 22(55 \%)$ children.

\section{Sibship comparison}

In addition to the seven sibships described above, there were five sibships for whom there was no parental information (four with two affected children and one with three affected children). In these 26 sibs from 12 families, there was considerable variation in heart abnormalities between sibs. For example, in three sibships, one child had a normal heart and the other sib had significant CHD. Within the sibships where all affected children had CHD there was variability in severity; for example, one sibship of three children had ventricular septal defect, coarctation of the aorta, and interrupted aortic arch type $\mathrm{B},{ }^{13}$ and another sibship had two children with patent ductus arteriosis (not related to prematurity) and one with transposition of the great arteries, atrial septal defect, and dextrocardia. Developmental status was similar for sibs in all but one case, where there was a marked difference; one sib required minimal help with schooling compared to her brother who had severe developmental delay. This sib pair are not in the parent/child group as there was no information available on their parents.

\section{Discussion}

The aim of this study was to provide data on which to base answers to questions in clinical practice, for example, the prognosis for children with a deletion within chromosome band $22 \mathrm{q} 11$ or the outlook following prenatal diagnosis. Clinicians from 23 European centres were sent a standard questionnaire which they completed after review of the patient or their notes. Usually the questionnaires were completed from notes held at the genetic centres where the laboratory diagnosis of the deletion was made. Often, no information was available for one or more sections of the questionnaire and this is reflected in the wide variation in patient numbers for the different sections' results. Absent data may mean that the tests had not been done or simply that the results were not available. For example, it is likely that most children will have had white cell counts though these were not recorded in half of the questionnaires. In contrast, we suspect that the absent data in the renal section is because a lower proportion of children will have had renal ultrasound. Unfortunately there is no way of distinguishing between these two situations for the data gathered. Missing data and paucity of clinical detail in some of the sections, for example, the behaviour and psychiatric sections, are disadvantages of the questionnaire approach. However, the large amount of data collected will be useful in counselling situations.

The proportion of inherited deletions within this series was $28 \%$, stressing the importance of studying both parents when a child is found to have a deletion. However, it is possible that some of these parents were tested because of clinical suspicion and that the proportion of inherited deletions would have been lower had all parents been tested. Of the 81 patients with an inherited deletion, there was a large maternal origin excess (61 maternal, 18 paternal).

In the majority of cases where the deletion was known to be de novo, the information came from FISH analysis and the parent of origin was not known. Of the 37 patients for whom parent of origin studies had been carried out, there was a paternal excess (24 paternal, 

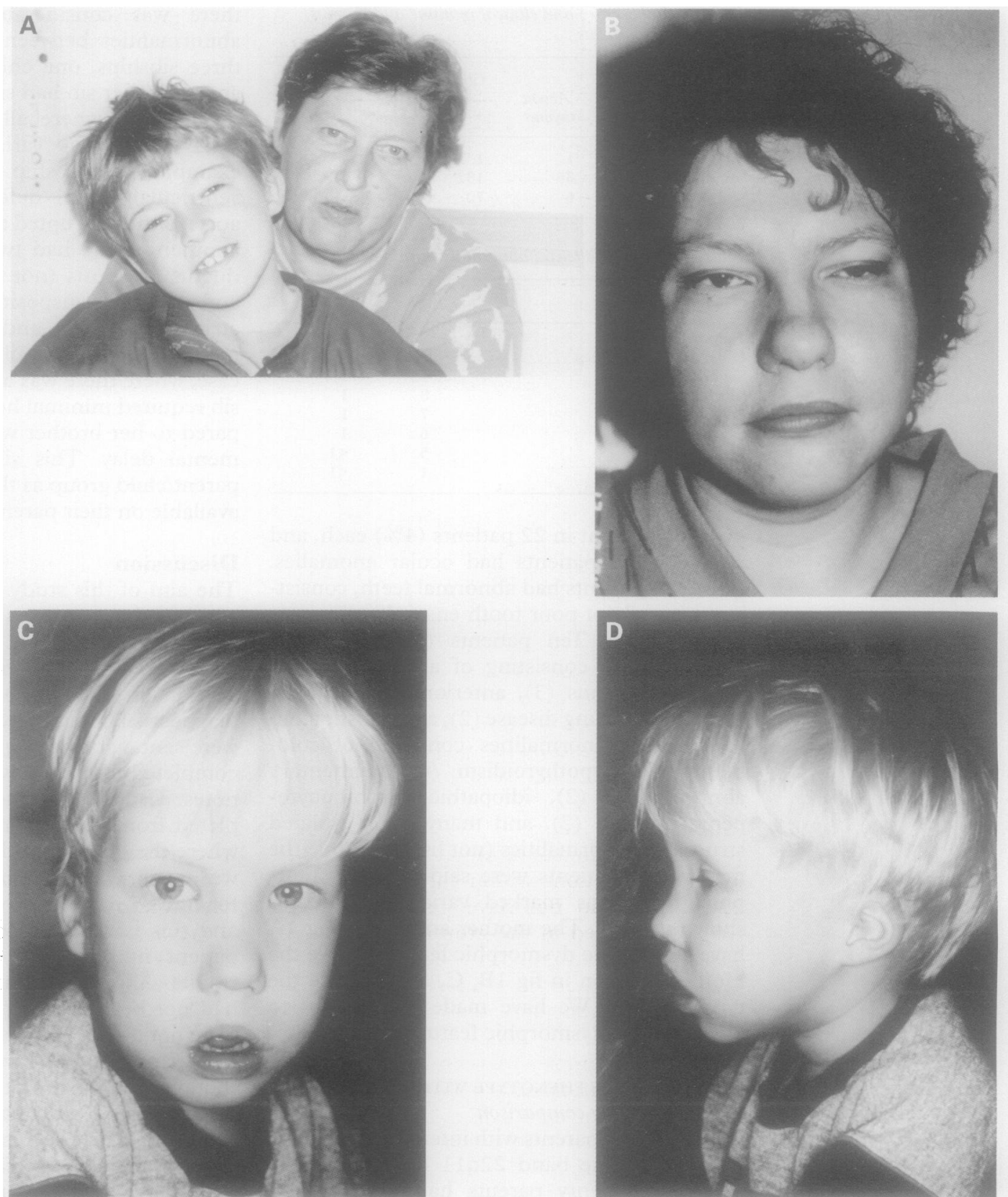

Figure 1 This figure shows two affected mothers and their affected sons. The mother and son in $(A)$ have very subtle dysmorphic features, while the mother and son in $(B),(C)$, and $(D)$ have more typical features, including small mouth, nose with bulbous tip, hypertelorism, and low set, simple ears.

13 maternal). In contrast, Demczuk et $a l^{13}$ combining their data with previous reports, found an excess of deletions of maternal origin (eight paternal, 24 maternal). Four cases (two paternal, two maternal) are in both series. When we pool data from this and the series of Demczuk et al,,$^{13}$ counting those four patients only once, there are 30 maternal and 35 paternal deletions. We conclude that there is not a major difference between parent of origin of de novo deletions.

Although most babies were born within the normal size range, 33/205 (16\%) are less than the 3rd and 147/205 (72\%) are less than the 50 th centile. This suggests there is an intrinsic problem causing growth retardation. For the majority of patients in the study we have birth weight and one set of subsequent childhood measurements, with serial information available on very few. Such data could be recorded on this database prospectively. The childhood measurements were frequently on a lower centile than birth weight, with $57 / 158(36 \%)<3$ rd and $131 / 158(83 \%)<50$ th centile. This may be related to feeding problems in the neonatal period or CHD. Recurrent infection is unlikely to play a role as this was a complication in only a small number of patients. Comparing the subgroups of patients with/without significant heart disease, $46 / 120(38 \%)$ were $<3$ rd versus $11 / 38$ (29\%), suggesting that, while CHD may contribute to growth failure, it is not the sole explanation and that these children are constitutionally small.

From the completed questionnaires, 209/ 338 patients $(62 \%)$ had either normal development or mild learning problems and $60 / 338$ $(18 \%)$ had moderate or severe learning problems. However, for 69/338 (20\%) developmental status was unknown. It seems likely that patients with mild learning problems account for more of these "unknown" cases than 
children with significant learning problems, as these would almost certainly have been recorded.

A total of $6.5 \%$ of adults had at least one episode of psychosis, a figure which is lower than recent papers ${ }^{14}{ }^{15}$ would suggest. This compares to a baseline population prevalence of psychosis in $5 \%$ of the adult population. ${ }^{16} \mathrm{It}$ is generally accepted that the percentage of psychosis in the learning disabled population is higher than in the general population but it is difficult to find a reliable figure. There was little detail about the psychiatric and behavioural problems in children or adults, highlighting this as an area in which more detailed studies are required.

The spectrum of heart defects seen in the study is similar to that previously reported, affecting predominantly both right and left outflow tracts. This is consistent with the hypothesis that the abnormal development is secondary to aberrant migration of neural crest into the branchial arches and outflow septum of the heart. It is of interest, however, that a few people had defects of structures that are thought not to be derived from the outflow tract, for instance, atrioventricular septal defect, atrial septal defect, and isomerism. All but one of the 44 deaths in our series were the result of CHD; death usually occurred within the first month (55\%) and in the majority $(86 \%)$ within six months. The study also provides an estimate of the proportion of subjects with deletions within chromosome band $22 \mathrm{q} 11$ who do not have cardiac problems $(25 \%)$. Included in the group of defects that were clinically insignificant were those children with isolated aberrant right or left subclavian artery and a right sided aortic arch. These were also found in association with other heart defects (for example, interrupted aortic arch or pulmonary atresia/ventricular septal defect). The presence of such defects has considerable diagnostic importance as they represent evidence of abnormal outflow tract/branchial arch artery development and should alert a clinician to the possible diagnosis of 22q11 deletion.

Renal abnormalities were a frequent finding, present in 49/136 (36\%) of patients. Many of these abnormalities require surgical or medical intervention to prevent complications such as hypertension and renal nephropathy. The high frequency of renal abnormalities suggests that renal ultrasounds should be a standard part of the investigations of these patients. Another genitourinary abnormality requiring surgical intervention is undescended testes, present in $8 \%$ of males.

Hypocalcaemia was present in 203/340 $(60 \%)$ of our patients, and was generally associated with presentation in the neonatal period. However, several patients presented with hypocalcaemia in childhood and one patient presented at the age of 18 years. In this group, it is not clear whether samples were taken following a seizure or for some other reason. Neonatal calcium measurements were not available for any of these children. The hypocalcaemia had resolved in $45 / 64(70 \%)$ of patients. In the patients remaining on calcium supplements, it was not known if parathyroid function had been reassessed.

The original description of the syndrome by DiGeorge $^{17}$ was of a child with hypoparathyroidism and recurrent infections and necropsy findings of three cases of absent thymus and parathyroid glands. Paediatric textbooks emphasise these aspects of the syndrome. However, in this large series of patients with deletions within chromosome 22q11, only three children had severe immunodeficiency, one previously reported by Wilson et al..$^{18}$ Even in those cases where the thymus was absent or where there were abnormal laboratory results, clinically significant immunological problems were uncommon.

Asymmetrical crying face has been reported previously as a common complication of patients with 22q11 deletions, ${ }^{6}$ but was reported in only 11 patients from four centres in this study. Either this is not as common as suggested or it is under-reported. All of the features of CHARGE association (Coloboma, Heart defects, Atresia choanae, Retarded growth and development, Genital hypoplasia, Ear anomalies), including facial asymmetry and facial nerve palsy, occur in this series of patients who have deletions within chromosome band 22q11. Cerebellar hypoplasia has been reported once before $e^{4}$ and there were two new cases in this series; it has been suggested that some cases of the $3 \mathrm{C}$ (craniocerebellocardiac) syndrome may in fact have deletions within chromosome band 22q11. This series has confirmed the previous case reports suggesting that polydactyly, ${ }^{5}$ craniosynostosis, ${ }^{19}$ and anal anomalies ${ }^{20}$ occur with this deletion, these being present in 1 to $2 \%$ of patients.

The parent group had less severe cardiac and developmental problems than the group as a whole. One interpretation of this is that they represent the phenotypic spectrum associated with the deletion better than the overall group and that there are many people in the community who have not come to medical attention or may be receiving some medical care, yet are not recognised as having a deletion within chromosome band 22q11. An alternative interpretation is that the milder end of the spectrum is more likely to reproduce. Perhaps the true spectrum lies somewhere between the two groups. In this series heart defects were always more severe in the children than in the parents. However, there has been one report of a child with a heart defect less severe than her affected mother. ${ }^{21}$ Developmental status was better in one, similar in seven, and worse in nine of the 17 cases. The palatal abnormalities were less severe in 10 of the children and similar to their parents in 12. The cardiac and palatal status, and development of these children are similar to the whole group. We suspect that the child-parent differences observed are because people with more representative heart defects and with moderate and severe mental handicap are less likely to have children of their own. Considerable variability was observed between sibs.

Most of the clinical findings in this study reflect previous reports. However, from previ- 
ous descriptions one would have expected immunological problems to be common but this was not the case. In contrast, renal problems were common, being present in $36 \%$ of those who had had abdominal ultrasound. This investigation should clearly be a routine investigation in these patients. Constitutional short stature has not been emphasised before but is part of the phenotype associated with this deletion. This study highlights the need for further investigation in some areas, especially that of behavioural and psychiatric complications. Twenty-eight percent of patients have inherited deletions, emphasising the need for studying both parents when a child is found to have a deletion.

We would like to thank Tina Buchholz (München), the many clinicians and scientists who are not coauthors but have provided patient information, and the subjects and families included in this study for their help and cooperation. This work has been supported by the Hemizygosity of Chromosome 22q11 and Human Birth Defects grant, GENE-CT93 0053, th Danish Medical Research Council, and Italian Telethon, contract NE.399 to BD.

1 Lipson AH, Yuille D, Angel M, et al. Velocardiofacial (Shprintzen) syndrome: an important syndrome for the dysmorphologist to recognise. $\mathcal{F}$ Med Genet $1991 ; 28: 596$ 604.

2 Demczuk S, Aurias A. DiGeorge syndrome and related syndromes associated with $22 \mathrm{q} 11.2$ deletions. A review. Ann Genet (Paris) 1995;38:59-76.

3 Wilson DI, Burn J, Scambler P, Goodship J. DiGeorge syndrome: part of CATCH 22. F Med Genet 1993;30:8526.

4 Lynch DR, McDonald-McGinn DM, Zackai EH, et al. Cerebellar atrophy in a patient with velocardiofacial syndrome. 7 Med Genet 1995;32:561-3.

5 Cormier-Daire V, Iserin L, Theophile D, et al. Upper limb malformations in DiGeorge syndrome. Am $\mathcal{F}$ Med Gene 1995;56:39-41.

6 Giannotti A, Digilio MC, Marino B, Mingarelli R, Dallapiccola B. Cayler cardiofacial syndrome and del 22q11: par of the CATCH22 phenotype. Am $\mathcal{F}$ Med Genet 1994;53 303-4.
7 Nickel RE, Pillers DM, Merkens M, et al. Velo-cardio-facial syndrome and DiGeorge sequence with meningomyelocele and deletions of the 22 sequence with meningomyelocele 52:445-9.

8 Lipson A, Emanuel BS, Colley P, Fagan K, Driscoll DA "CATCH 22" sans cardiac anomaly, thymic hypoplasia cleft palate, and hypocalcaemia: cAtch 22 . A common result of 22q11 deficiency? $₹$ Med Genet 1994;31:741.

9 Scirè G, Dallapiccola B, Iannetti $P$, et al. Hypoparathyroidism as the major manifestation in two patients with 22q11 deletions. Am $\mathcal{F}$ Med Genet 1994;52:478-82.

10 Greig F, Paul E, DiMartino-Nardi J, Saenger P. Transient congenital hypoparathyroidism: resolution and recurrence in chromosome 22q11 deletion. $\mathcal{F}$ Pediatr 1996;128:563-7.

11 Goldberg R, Motzkin B, Marion R, Scambler PJ, Shprintzen RJ. Velo-cardio-facial syndrome: a review of 120 patients. Am ₹ Med Genet 1993;45:313-19.

12 Brondum-Nielsen $\mathrm{K}$, Christensen $\mathrm{K}$. Chromosome 22q11 deletion and other chromosome aberrations in cases with cleft palate, congenital heart defects and/or mental disability. A survey based on the Danish Facial Cleft Register. Clin Genet (in press).

13 Demczuk S, Levy A, Aubry M, et al. Excess of deletions of maternal origin in the DiGeorge/velo-cardio-facial syndromes. A study of 22 new patients and review of the dromes. A study of 22 new patients

14 Shprintzen RJ, Goldberg R, Golding-Kushner KJ, Marion $R W$. Late-onset psychosis in the velo-cardio-facial syndrome. Am $\mathcal{F}$ Med Genet 1992;42:141-2.

15 Pulver AE, Nestadt G, Goldberg R, et al. Psychotic illness in patients diagnosed with velo-cardio-facial syndrome and their relatives. $\mathcal{F}$ Nerv Ment Dis 1994;128:476-78.

16 McGuffin P, Owen MJ, O'Donovan MC, Thapar A, Gottesman II. Seminars in psychiatric genetics. London: Gaskell, 1994.

17 DiGeorge AM. Congenital absence of the thymus and its immunologic consequences: concurrence with congenital hypothyroidism. In: Good RA, Bergsma D, eds. Birth defects 1968. New York: March of Dimes, National Foundation Press, 1968:116-21.

18 Wilson DI, Cross IE, Goodship JA, et al. A prospective cytogenetic study of 36 cases of DiGeorge syndrome. Am $\mathcal{F}$ Hum Genet 1992;51:957-63.

19 Dean JCS, Cole GF, Appleton RE, et al. Cranial hemihypertrophy and neurodevelopment prognosis. $f$ Med Genet 1990;27:160-4.

20 Worthington S, Colley A, Fagan K, Dai K, Lipson AH. Anal anomalies: an uncommon feature of velocardiofacial (Shprinzen) syndrome? $¥ M$ Med Genet 1997;34:79-82A.

21 Holder SE, Winter RM, Kamath S, Scambler PJ. Velocardiofacial anomaly in a mother and daughter: variability of the clinical phenotype. $\mathcal{F}$ Med Genet 1993;30:825-7. 